\title{
Multi-syringe flow injection system for the determination of available phosphorus in soil samples
}

\author{
M. INÊS G.S. ALMEIDA $\uparrow$ MARCELA A. SEGUNDO†, \\ JOSÉ L.F.C. LIMAł and ANTÓNIO O.S.S. RANGEL*† \\ $\dagger$ †scola Superior de Biotecnologia, Universidade Católica Portuguesa, Rua Dr. António \\ Bernardino de Almeida, 4200-072 Porto, Portugal \\ †Requimte, Serviço de Química-Física, Faculdade de Farmácia, Universidade do Porto, \\ Rua Aníbal Cunha, 164, 4050-047 Porto, Portugal
}

\begin{abstract}
Considering the importance of monitoring the levels of nutrients present in soils and their availability to plants, an automatic methodology is proposed based on multi-syringe flow injection analysis (MSFIA) for the spectrophotometric determination of available phosphorus in soil extracts. This fully computerized flow technique allowed the development of a flow network where sample and reagents were intercalated and sent further towards the detection system. The colorimetric determination was based on the molybdenum blue method with ascorbic acid as reducing reagent and the Egner-Riehm method was applied to extract phosphorus from soil samples. A linear calibration curve was obtained between 0.75 and $15.0 \mathrm{mg} \mathrm{L}^{-1}$. A determination frequency of $15 \mathrm{~h}^{-1}$ was achieved, with good repeatability for 12 consecutive injections of soil extracts $(\mathrm{RSD}<1.7 \%)$. The results obtained from 12 soil samples were statistically comparable to those attained by the usual batch method.
\end{abstract}

Keywords: Multi-syringe flow injection analysis; Available phosphorus; Soil; Spectrophotometry

\section{Introduction}

Soil is an important component in continental ecosystems, as it plays the role of storehouse and supplier of the necessary nutrients for the growth of plants. Among the elements considered as macronutrients, phosphorus is essential to all known life forms because it is a key element in many physiological and biochemical processes. Nevertheless, the amount of plant-available phosphorus in the soil tends to be far less than the plant requires. In consequence, the phosphorus in the soil has to be replenished by addition of fertilizers containing this element [1]. While fertilizers provide many important benefits in crop production, their improper use can harm the environment and affect water quality since phosphorus $(\mathrm{P})$ in run off from agricultural land is an important component of nonpoint source pollution, accelerating eutrophication 
of lakes and streams [2]. Recently, there has been interest in the calibration of agronomic soil tests to predict the risk of $\mathrm{P}$ transport in run off. The values obtained from these tests, in combination with soil landscape information, can be used to establish guidelines for $\mathrm{P}$ management in agricultural soils [3, 4]. Therefore, the development of analytical procedures that allow a rapid and reliable evaluation of soil conditions can make a significant contribution to this field.

Over the years, flow techniques have shown their suitability for this role. Their evolution and perspectives are described in a recent review [5]. Multi-syringe flow injection analysis (MSFIA) is the most recent technique, proposed by Cerdà et al. [6], and it was devised to take the advantage of the preceding continuous-flow techniques. Therefore, the MSFIA technique can provide a sampling rate similar to that in flow injection analysis (FIA) [7], with the robustness, versatility, and economy of reagent use of sequential injection analysis (SIA) [8] and multi-commuted flow injection analysis (MCFIA) [9].

In the present work, the application of MSFIA to soil analysis is proposed. The main objective is the development of a computer-controlled flow system designed to determine available phosphorus in soil extracts. The molybdenum blue method was chosen for the colorimetric determination, using ascorbic acid as reducing agent and antimony to accelerate the reduction to the blue complex.

Several automatic methods have been proposed for the determination of available phosphorus in soils using segmented flow analysis (SFA) and FIA systems. To our best knowledge, there is no report on any SIA or MCFIA system dedicated to this determination in soil extracts.

The spectrophotometric detection of micro amounts of phosphate using an SFA system was reported, by Warrell and Moody [10]. Nevertheless, inaccurate results were reported due to coloured extracts. To overcome this problem, Novozamsky et al. [11] included a dialysis device in their SFA system. Their colorimetric determination was based on the reaction between phosphomolybdate and Malachite Green, to give a green complex. The formation of a green coating was reported at the point where Malachite Green was added to the reagent stream. Hence, the coil had to be replaced once a week. A similar SFA system was developed by Coutinho [12], using the molybdenum blue method, and no coating on the coil was observed.

The spectrophotometric determination of available phosphorus in soils by FIA has also been proposed by Sun et al. [13], García et al. [14] and Coventry et al. [15]. All three proposals were based on the molybdenum blue method, using stannous [tin (II)] chloride as reducing agent. However, in the first work, sample pretreatment with sulfuric acid was required to avoid the formation of air bubbles from the $\mathrm{NaHCO}_{3}$ extraction solution. Previous dilution of soil samples was required in the other FIA systems in order to fit the concentration range [14] or to reduce the salt concentration [15]. Finally, a potentiometric FIA system was also developed for this determination [16], but it was only applied to spiked soil extracts.

\section{Experimental}

\subsection{Reagents and solutions}

For the preparation of all solutions, water from a MilliQ system (resistivity > $18 \mathrm{M} \Omega \mathrm{cm}$ ) was applied and all chemicals were analytical-reagent grade. 
For extraction of phosphorus from soil samples, $200 \mathrm{~mL}$ of ammonium lactate-acetic acid solution was prepared by mixing $22.5 \mathrm{~mL}$ of concentrated aq. lactic acid $(d=1.21$; $85 \%$; Sigma), $5 \mathrm{~mL}$ of concentrated aq. acetic acid $(d=1.05 ; 100 \%$; Merck), and $15.5 \mathrm{~mL}$ of concentrated aq. ammonia $(d=0.910 ; 25 \%$; Merck). Subsequently, this mixture was diluted (1:10) with water and its $\mathrm{pH}$ should then be $3.75 \pm 0.05$.

A stock solution of $250 \mathrm{mg} \mathrm{P} \mathrm{L}^{-1}$ was prepared by dissolving $1.099 \mathrm{~g}$ of potassium dihydrogen phosphate (Merck) per liter of water. Working standards from 0.75 to $15 \mathrm{mg} \mathrm{P} \mathrm{L}^{-1}$ were obtained by rigorous dilution of stock solution and addition of $10 \mathrm{~mL}$ of concentrated extraction solution for a final volume of $100 \mathrm{~mL}$. Glassware needed for phosphorus determination was soaked in $1 \mathrm{~mol} \mathrm{~L}^{-1}$ nitric acid (Merck) and rinsed with water.

Aq. $2.5 \mathrm{~mol} \mathrm{~L}^{-1}$ sulfuric acid solution (A) was prepared by dilution of concentrated sulfuric acid ( $d=1.98,98 \%$; Merck). Two stock solutions (B and C) were prepared from ammonium heptamolybdate tetrahydrate $\left(100 \mathrm{~g} \mathrm{~L}^{-1}\right.$; Merck) and potassium antimony(III) oxide tartrate hemihydrate $\left(2.74 \mathrm{~g} \mathrm{~L}^{-1}\right.$; Merck) by dissolving $10 \mathrm{~g}$ and $0.274 \mathrm{~g}$ in $100 \mathrm{~mL}$ of water, respectively.

The colour reagent consisted of a mixture of the previous stock solutions: $100 \mathrm{~mL}$ of solution $\mathrm{A}, 80 \mathrm{~mL}$ of solution $\mathrm{B}$, and $7.30 \mathrm{~mL}$ of solution $\mathrm{C}$ were mixed and subsequently made up to $500 \mathrm{~mL}$ with water. The ascorbic acid solution (reducing reagent) was obtained by dissolving $0.162 \mathrm{~g}$ of ascorbic acid (Merck) in $100 \mathrm{~mL}$ of water. The carrier solution was $1 \times 10^{-3} \mathrm{~mol} \mathrm{~L}^{-1} \mathrm{NaOH}$ (Merck).

\subsection{Apparatus}

A multi-syringe burette (Crison Instruments, Allela, Spain) was used to propel all solutions through the flow network. This device is a multiple-channel piston pump, driven by the single motor of an automatic burette and controlled by computer software through a serial port. The multi-syringe may combine up to four syringes of different capacities. In this work only three of them were necessary: a five $m L$ syringe was placed in position 1 and ten $\mathrm{mL}$ syringes were placed in the other positions. A three way commutation valve (NResearch, Caldwell, NJ, USA) was connected at the top of each syringe and two extra commutation valves were included in the manifold. For all valves, the exchange options were classified in on/off lines. The 'on' line was assigned to the solution flasks, and the 'off' line was reserved for the flow network.

A personal computer (Samsung SD 700) running lab-made software written in QuickBasic 4.5 (Microsoft) controlled the multi-syringe operation (piston movement and position of all commutation valves).

As detection system, a Thermo-spectronic (Cambridge, UK) Helios $\gamma$ UV/Vis spectrophotometer equipped with a Hellma (Mullheim/Baden, Germany) 178.712-QS

flow-through cell (internal volume $18 \mu \mathrm{L}$ ) was used and the wavelength was set at $880 \mathrm{~nm}$. The analytical signals were recorded in a Kipp \& Zonen BD 111 strip chart recorder.

\subsection{Manifold}

All connections of the designed manifold, described in figure 1, were made of PTFE tubing ( $0.8 \mathrm{~mm}$ i.d.) with Gilson (Villiers-le-Bel, France) end-fittings and connectors, except the reaction coil ( $\mathrm{RC})$ tube, which was made from FEP tubing ( $0.8 \mathrm{~mm}$ i.d.). 




Figure 1. MSFIA manifold for the determination of phosphorus in soil samples: MS, multi-syringe; $\mathrm{S} i$, syringe; $\mathrm{V} i$, solenoid valves; $\mathrm{N}$, 'on' position (dotted line); F, 'off' position (solid line); HC, holding coil; RC, reaction coil; D, detector; r, recorder; X, confluence; Li, PTFE connections; C, carrier; R1, color reagent; $\mathrm{R} 2$, reducing reagent; $\mathrm{SE}$, soil extract; $\mathrm{W}$, waste.

The physical properties of FEP (more rigid and slightly less porous than PTFE) minimized the retention of the molybdenum blue-coloured complex in the tubing walls. All tubing was purchased from Omnifit (Cambridge, UK).

The holding coil (HC) and the RC were 400 and $100 \mathrm{~cm}$ long, respectively. The tubing connections shown in figure 1 as L1 and L2 were both $10 \mathrm{~cm}$ long.

\subsection{MSFIA Procedure}

The procedure referred to below was applied to the MSFIA determination of available phosphorus and it is described in table 1. This procedure was divided in two parts: the first consisted of the colorimetric determination (steps $A-G$ ) and the second corresponded to the washing of the system and the preparation of the next analytical cycle (steps $\mathrm{H}-\mathrm{L}$ ).

The first step consisted of dispensing carrier and reagents toward their own flasks (valves in position 'on') to eliminate possible bubbles that might be placed at the head of each syringe. Afterwards a $1.500 \mathrm{~mL}$ sample was aspirated into the HC (step B). Then, it was necessary to propel this sample up to the confluence X (step C) before starting the colorimetric determination. As tube L2 became filled with sample, it was rinsed with reagents dispensed towards waste (step D). Before the colorimetric reaction started, the baseline was set by dispensing reagents through the $\mathrm{RC}$ (step E). Subsequently, $0.100 \mathrm{~mL}$ of the sample was propelled into the RC (step F) and pushed by reagents (R1 and R2) towards the detection system while reaction took place (step G). Steps F and $G$ were repeated three times in the same analytical cycle. To prepare the system for the next operation sequence, the $\mathrm{HC}$ was washed with carrier (steps $\mathrm{H}$ and $\mathrm{J}$ ). After that, reagents were dispensed through the reaction coil to set the 


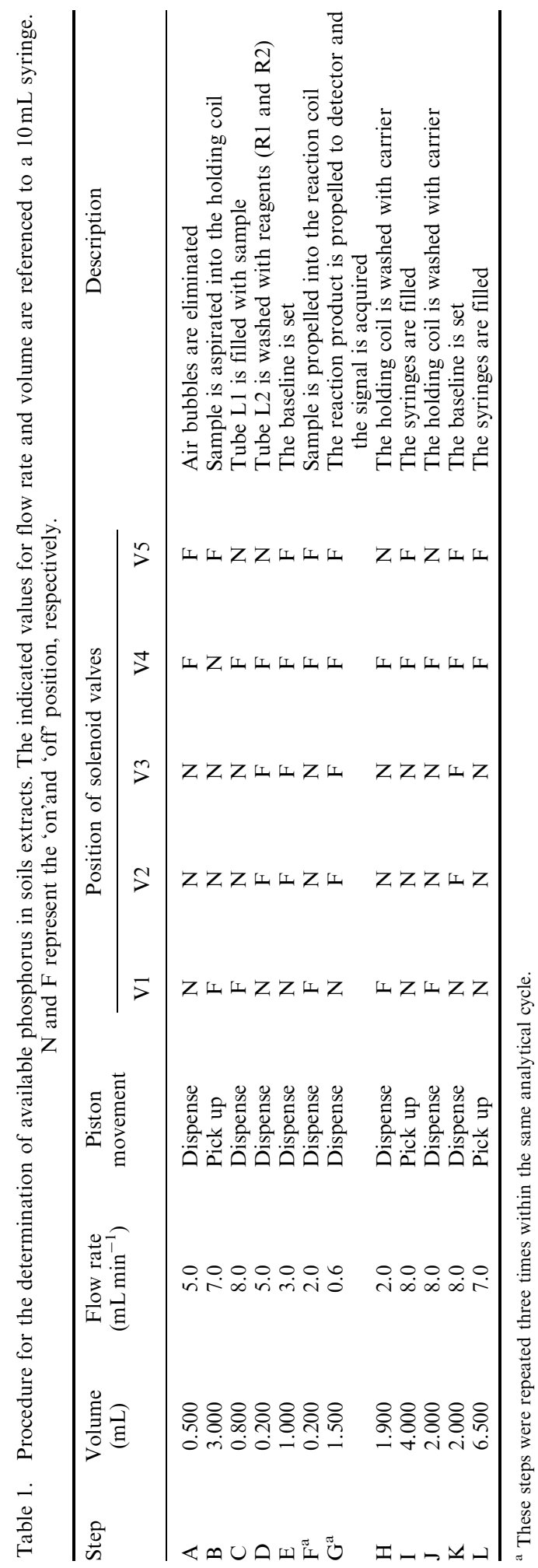


baseline again (step K). After filling the syringes up to $70 \%$ of their capacity (step I), the system was ready to begin another cycle that included three determinations.

In order to include a stop period for reaction development before detection, step $\mathrm{G}$ (table 1) was replaced by three steps, where the position of the commutation valves was kept constant. In the first and third steps, R1 and R2 (figure 1) were propelled towards the detector at $0.60 \mathrm{~mL} \mathrm{~min}^{-1}(0.125 \mathrm{~mL})$ and $1.50 \mathrm{~mL} \mathrm{~min} \mathrm{~m}^{-1}$ $(1.375 \mathrm{~mL})$, respectively. These experimental conditions were applied during the study of some variables of the flow system.

\subsection{Sample treatment}

Soil samples were treated in the same way for both MSFIA and usual batch method using the Egner-Riehm method [17], currently applied in Portuguese laboratories. Hence, $2.5 \mathrm{~g}$ of soil were weighed and $50 \mathrm{~mL}$ of ammonium lactate-acetic acid extraction solution were added. This mixture was shaken for $4 \mathrm{~h}$ at $20^{\circ} \mathrm{C}$, and filtered through paper. The filtrate was then introduced into the MSFIA system and tested by the usual batch procedure.

\section{Results and discussion}

\subsection{MSFIA system for the determination of available phosphorus}

The main purpose of this work was to develop a computer-controlled flow system enabling the determination of available phosphorus using spectrophotometric detection. Hence, a multi-syringe flow system was devised and some flow and chemical parameters were studied. The range of values tested for each parameter and the chosen conditions for its operation are presented in table 2.

In multi-syringe flow systems it is not feasible to introduce the sample into the system through one of the available syringes as this would require a large number of washing steps to avoid carry-over between consecutive samples. Hence, other devices (selection or commutation valves) must be incorporated to the manifold to provide access to these solutions. Therefore, valve V4 was included in the present manifold.

The volume of sample introduced into the system was defined by the time and flow rate applied during its aspiration/propulsion. As a holding coil was placed between valve V4 and the multi-syringe, it was possible to collect a large sample volume and introduce smaller portions (injection volume) into the system by commutation of valve V1 (figure 1 and table 1 , steps $F$ and $G$ ) while valve V4 is connected to the flow system. This strategy was applied in the present flow system to allow the

Table 2. Range of values used in the study of system variables and the final chosen operating conditions.

Parameter

Molybdate concentration ( $\left.\mathrm{g} \mathrm{L}^{-1}\right)$

Antimony concentration $\left(\mathrm{g} \mathrm{L}^{-1}\right)$

Sulfuric acid concentration $\left(\mathrm{mol} \mathrm{L}^{-1}\right)$

Injection volume $(\mu \mathrm{L})$

Time interval for flow stop during reaction step (s)

Flow rate of reaction step $\left(\mathrm{mL} \mathrm{min}^{-1}\right)$

Range
$2-32$
$0.005-0.080$
$0.1-0.7$
$50-200$
$0-90$
$0.6-2$

Chosen value

16

0.040

0.5

100

0

0.6 
performance of three consecutive determinations after filling the holding coil with sample. The sample volume was fixed at $1.5 \mathrm{~mL}$.

The build-up of molybdenum blue complex into the tubing walls has been reported. To minimize this, the carrier solution was $1 \times 10^{-3} \mathrm{~mol} \mathrm{~L}^{-1}$ aq. $\mathrm{NaOH}$. Ascorbic acid was chosen as reducing reagent, and its concentration was fixed at $9.2 \times 10^{-3} \mathrm{~mol} \mathrm{~L}^{-1}$. First, the introduction of a stop period for reaction development before detection was considered important to improve sensitivity. Hence, step G (table 1) was divided into three steps as described in section 2.4. The stop period was varied between 0 and $90 \mathrm{~s}$, while the injection volume was $0.100 \mathrm{~mL}$ and the concentration of sulfuric acid was $0.4 \mathrm{~mol} \mathrm{~L}^{-1}$. The concentration of ammonium heptamolybdate tetrahydrate and potassium antimony (III) oxide tartrate hemihydrate solutions was kept at 16 and $0.04 \mathrm{~g} \mathrm{~L}^{-1}$, respectively. The sensitivity was assessed through the slope of the calibration curve established between 0.75 and $5.0 \mathrm{mg} \mathrm{PL}^{-1}$. The experiment without flow stop revealed a low sensitivity ( $11 \%$ of the value obtained for $90 \mathrm{~s}$ ). The sensitivity achieved for $15,30,45$ and $60 \mathrm{~s}$ was $33,55,65$ and $76 \%$ of that obtained for $90 \mathrm{~s}$, respectively. Nevertheless, when a stop period of $90 \mathrm{~s}$ was applied, it was noticed the build-up of molybdenum-blue complex in tube walls, giving results with poor repeatability. Hence, a stop period of $60 \mathrm{~s}$ was chosen for further studies.

The influence of the composition of the colour reagent (R1) was studied by varying the concentration of ammonium heptamolybdate tetrahydrate (molybdate), potassium antimony(III) oxide tartrate hemihydrate (antimony) and the concentration of sulfuric acid. These trials were performed under the same conditions described above.

Different concentrations of both molybdate and antimony were tested, maintaining the same ratio $(1: 400)$. The concentration range studied for molybdate was $2-32 \mathrm{~g} \mathrm{~L}^{-1}$ and for antimony was $0.005-0.080 \mathrm{~g} \mathrm{~L}^{-1}$. An increase in the concentration values of both reagents $\left(2,4,8\right.$ and $16 \mathrm{~g} \mathrm{~L}^{-1}$ for molybdate and $0.005,0.01,0.02$ and $0.04 \mathrm{~g} \mathrm{~L}^{-1}$ for antimony) increased sensitivity $\left(16,54\right.$ and $72 \%$ of that obtained for $16 \mathrm{~g} \mathrm{~L}^{-1}$ of molybdate and $0.040 \mathrm{~g} \mathrm{~L}^{-1}$ of antimony). When concentration values higher than $16 \mathrm{~g} \mathrm{~L}^{-1}$ for molybdate were tested, retention of molybdenum-blue complex in tube walls occurred. As the best results concerning sensitivity were attained with $16 \mathrm{~g} \mathrm{~L}^{-1}$ of molybdate and $0.04 \mathrm{~g} \mathrm{~L}^{-1}$ of antimony, these values were kept for further studies.

The formation of molybdenum blue coloured complex is highly affected by the $\mathrm{pH}$ value. Hence, the concentration of sulfuric acid was varied between $0.1 \mathrm{~mol} \mathrm{~L}^{-1}$ and $0.7 \mathrm{~mol} \mathrm{~L}^{-1}$, using the conditions described above. The sensitivity achieved for $0.1,0.2$, 0.3 and $0.4 \mathrm{~mol} \mathrm{~L}^{-1}$ was $64,74,74$ and $87 \%$ of the obtained for $0.5 \mathrm{~mol} \mathrm{~L}^{-1}$. Above this value, the sensitivity decreased (sensitivity obtained for $0.7 \mathrm{~mol} \mathrm{~L}^{-1}$ was $85 \%$ of the obtained for $0.5 \mathrm{~mol} \mathrm{~L}^{-1}$ ). Therefore, the chosen concentration was $0.5 \mathrm{~mol} \mathrm{~L}^{-1}$.

The injection volume was studied between 0.050 and $0.200 \mathrm{~mL}$. Volumes larger than $0.200 \mathrm{~mL}$ were not tried due to restrictions imposed by the holding coil volume. The sensitivity achieved for $0.050 \mathrm{~mL}$ of injection volume was $77 \%$ of the obtained for $0.200 \mathrm{~mL}$, and for $0.075,0.100$ and $0.150 \mathrm{~mL}$ the sensitivity was about $90 \%$ of that obtained for $0.200 \mathrm{~mL}$. It was also noticed that the baseline stability was affected when injection volumes higher than $0.100 \mathrm{~mL}$ were applied. Therefore, the injection volume chosen for further studies was $0.100 \mathrm{~mL}$.

In the present manifold, different strategies for addition of reagents to sample could be implemented through software control, without physical reconfiguration. This was possible since reagent solutions and sample were sent towards the detector through confluence $\mathrm{X}$ (figure 1). Therefore, the sample could be placed between two plugs 
of reagents or it could merge with reagents by changing the position of the commutation valves in the multi-syringe. This 'merging' approach was also tested, using different sample volumes. The results were similar to those obtained when the first approach was applied which indicated that good mixture conditions were achieved in the first place.

Finally, the flow rate of step $\mathrm{G}$ was varied between 0.6 and $2.0 \mathrm{~mL} \mathrm{~min}^{-1}$, in order to increase the time before detection without stopping the flow. The sensitivity achieved for $1.0,1.5$ and $2.0 \mathrm{~mL} \mathrm{~min}^{-1}$ was 74,54 and $41 \%$ of the obtained for $0.6 \mathrm{~mL} \mathrm{~min}^{-1}$. When compared to the other approach, it was verified that the sensitivity achieved by stopping the flow before the signal registration was 3.6-times better than without it (flow rate of $0.6 \mathrm{~mL} \mathrm{~min}^{-1}$ ). However, the retention of the molybdenum-blue complex in tube walls was more pronounced in the first situation, increasing the washing of the system and the preparation to the next determination without carry-over. Hence, it was chosen to eliminate the stop period and the application of a flow rate of $0.6 \mathrm{~mL} / \mathrm{min}$ for propelling the reaction product through the detection system.

\subsection{Features of the system}

A signal register for the determination of available phosphorus in four soil samples is depicted in figure 2. A linear response between absorbance and phosphorus concentration was obtained over the range of $0.75-15.0 \mathrm{mg} \mathrm{P} \mathrm{L}^{-1}$.

The analytical cycle of the present methodology can be divided in two parts: colorimetric determination (Table 1, steps A-G) and washing of the system (Table 1,

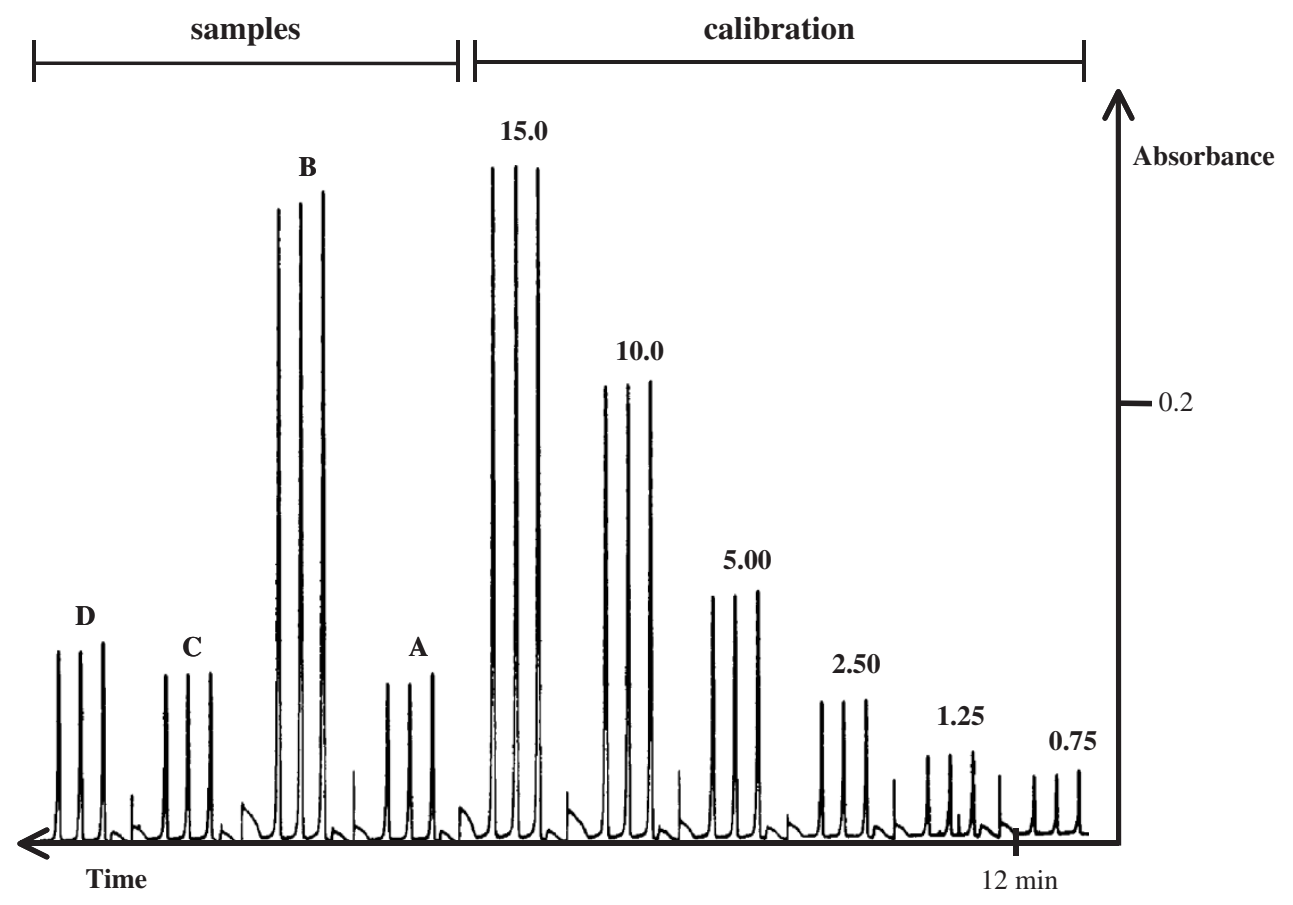

Figure 2. Recorder output for the determination of available phosphorus in soil extracts (A to D). In this case the correspondent calibration curve is: Absorbance $=0.0203[\mathrm{P}]+0.0122, R=0.9999$, for phosphorus standards between 0.75 and $15.0 \mathrm{mg} \mathrm{P} \mathrm{L}^{-1}$. 


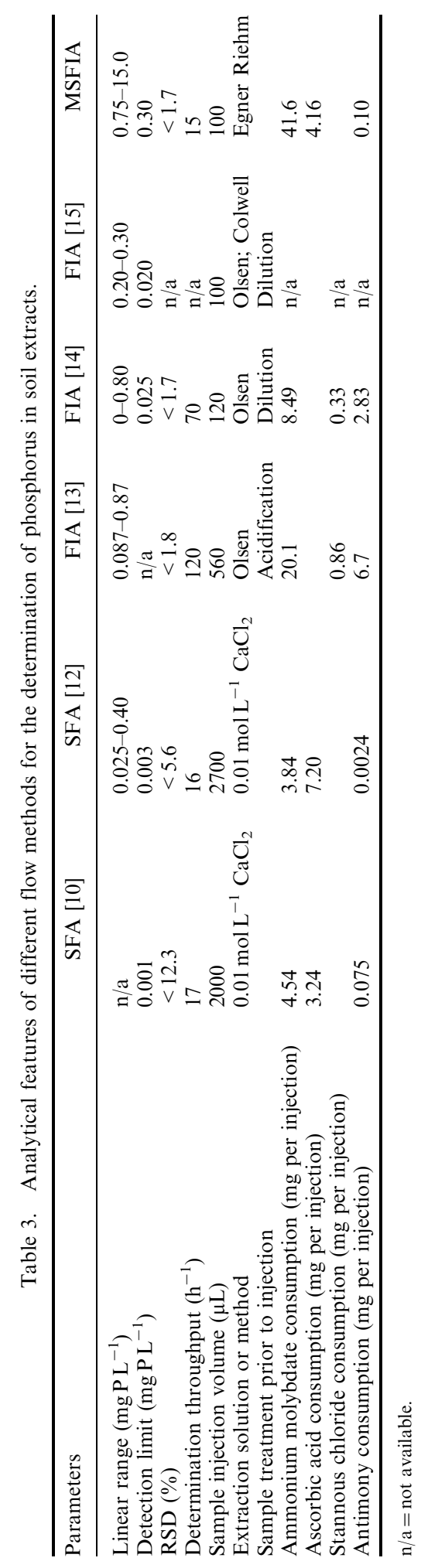


steps $\mathrm{H}-\mathrm{L}$ ). Considering that the time required for data transference between the computer and the multi-syringe must also be accounted, the whole analytical cycle took $701 \mathrm{~s}$ : $60 \mathrm{~s}$ from step A to E, $468 \mathrm{~s}$ for the colorimetric determination $(3 \times 156 \mathrm{~s}$ considering three replicate determinations) and $173 \mathrm{~s}$ for the washing of the system. In this case, the determination frequency was 15 per hour and the sample frequency was about 5 per hour considering three replicate determinations for each sample.

The detection limit for this determination using the developed MSFIA system was $0.3 \mathrm{mg} \mathrm{PL}^{-1}$, calculated as the concentration corresponding to the blank signal plus three times the standard deviation of twelve consecutive blank injections [18]. The blank signal was obtained by injecting a solution with the same composition as the standards, except for the phosphate.

The repeatability of this system was assessed from twelve injections of three soil extracts containing different concentrations of phosphorus $(2.4,8.3$ and 13.5 $\mathrm{mg} \mathrm{PL}^{-1}$ ). The corresponding relative standard deviation values were $1.2,1.7$, and $0.9 \%$, respectively.

For comparison purposes, the analytical features of the different flow methods for determination of $\mathrm{P}$ in soil extracts and which resort to molybdenum blue chemistry, are displayed in table 3. When the MSFIA procedure is compared with those already proposed, similar values are obtained to those attained by FIA methods regarding injection volumes and repeatability. The sampling frequency is lower than that obtained in FIA but similar to that attained in SFA systems.

The concentration values included in the determination range of the MSFIA system are about ten times larger than the values determined by the other systems. This feature allowed the direct introduction of soil extracts, even from soil samples containing large amounts of phosphorus. As a consequence, the reagent consumption per determination is also increased when compared with the methodologies proposed previously.

\subsection{Application to soil samples}

Twelve soil samples obtained from Portugal (Esposende, Vila do Conde), were analyzed by the proposed MSFIA procedure $\left(C_{\text {MSFIA }}\right)$ and by the usual batch method $\left(C_{\text {batch }}\right)$ [17]. The results, together with the corresponding absolute and relative deviations, are presented in table 4.

Table 4. Results obtained by MSFIA methodology $\left(C_{\text {MSFIA }}\right)$ and by the reference method $\left(C_{\text {batch }}\right)$ for the determination of available phosphorus in soil extracts. Absolute (AD) and relative deviations (RD) are also given.

\begin{tabular}{|c|c|c|c|c|}
\hline Soil samples & $\mathrm{C}_{\text {MSFIA }}\left(\mathrm{mg} \mathrm{P} \mathrm{L}^{-1}\right)$ & $\mathrm{C}_{\text {batch }}\left(\mathrm{mg} \mathrm{P} \mathrm{L}^{-1}\right)$ & $\mathrm{AD}\left(\mathrm{mg} \mathrm{P} \mathrm{L}^{-1}\right)$ & $\mathrm{RD}(\%)$ \\
\hline 1 & $6.69 \pm 0.07$ & $6.55 \pm 0.16$ & 0.14 & 2.1 \\
\hline 2 & $3.12 \pm 0.08$ & $3.11 \pm 0.11$ & 0.01 & 0.3 \\
\hline 3 & $8.74 \pm 0.09$ & $8.51 \pm 0.10$ & 0.23 & 2.7 \\
\hline 4 & $6.05 \pm 0.06$ & $5.96 \pm 0.24$ & 0.09 & 1.5 \\
\hline 5 & $14.7 \pm 0.2$ & $15.1 \pm 0.2$ & -0.4 & -2.6 \\
\hline 6 & $17.2 \pm 0.1$ & $17.0 \pm 0.3$ & 0.2 & 1.2 \\
\hline 7 & $1.33 \pm 0.00$ & $1.31 \pm 0.07$ & 0.02 & 1.5 \\
\hline 8 & $2.85 \pm 0.03$ & $2.68 \pm 0.11$ & 0.17 & 6.3 \\
\hline 9 & $14.3 \pm 0.2$ & $13.9 \pm 0.1$ & 0.4 & 2.9 \\
\hline 10 & $3.17 \pm 0.03$ & $2.93 \pm 0.02$ & 0.24 & 8.2 \\
\hline 11 & $3.86 \pm 0.11$ & $3.85 \pm 0.06$ & 0.01 & 0.3 \\
\hline 12 & $2.64 \pm 0.03$ & $2.48 \pm 0.04$ & 0.16 & 6.5 \\
\hline
\end{tabular}


To evaluate the accuracy of the developed methodology, a statistical treatment of MSFIA results was established: $C_{\text {MSFIA }}=0.995( \pm 0.025) \quad C_{\text {batch }}+0.08( \pm 0.22)$, $R=0.9993$, at $95 \%$ significance level. From these data, it is clear that the calculated slope and intercept do not differ significantly from the values 1 and 0 , respectively. Thus, there is no evidence for systematic differences between the proposed methodology and by the usual batch method [19].

\section{Conclusions}

The MSFIA technique was applied, for the first time, to soil analysis, providing reliable results for the spectrophotometric determination of available phosphorus in this matrix. Moreover, the proposed system can be regarded as a screening tool in environmental analysis, since large amounts of phosphorus can be determined (15-300 $\mathrm{mg} \mathrm{P} \mathrm{kg}^{-1}$ ), providing information about zones where water contamination by excessive phosphate might occur.

Some advantages of the proposed MSFIA system compared with the previously described SFA and FIA systems for the same determination can be stated. First, soil extracts were introduced directly into the present system, without any previous treatment. Additionally, coating of tubes with the molybdenum blue complex was prevented by including $\mathrm{NaOH}$ in the washing carrier solution. Furthermore, MSFIA systems surpass SFA and FIA systems as far as automation is concerned [5]. This type of system is fully computerized, allowing software control of many features (volumes, flow rate, reaction time) without any physical reconfiguration, and dispensing with the need for full time human attention.

\section{Acknowledgements}

The authors thank IFADAP for financial support through project AGRO 273. M. I. G. S. Almeida thanks FCT and FSE (III Quadro Comunitário de Apoio) for the grant SFRH/BD/8541/2002.

\section{References}

[1] A.E. Johnston, I. Steén. In Understanding Phosphorus and its Use in Agriculture, European Fertilizer Manufactures Association, Brussels (2000).

[2] T.C. Daniel, A.N. Sharpley, J.L. Lemunyon. J. Environ. Quality, 27, 251 (1998).

[3] R.W. McDowell, A.N. Sharpley. Agric. Ecosyst. Environ., 102, 17 (2004).

[4] A.M. Ebeling, L.R. Cooperband, L.G. Bundy. Commun. Soil Sci. Plant Anal., 34, 1897 (2003).

[5] M.A. Segundo, A.O.S.S. Rangel. J. Flow Injection Anal., 19, 3 (2002).

[6] V. Cerdà, J.M. Estela, R. Forteza, A. Cladera, E. Becerra, P. Altimira, P. Sitjar. Talanta, 50, 695 (1999).

[7] J. Ruzicka, E.H. Hansen. Anal. Chim. Acta, 78, 145 (1975).

[8] J. Ruzicka, G.D. Marshall. Anal. Chim. Acta, 237, 329 (1990).

[9] B.F. Reis, M.F. Giné, E.A.G. Zagatto, J.L.F.C. Lima, R.A. Lapa. Anal. Chim. Acta, 293, 129 (1994).

[10] L.A. Warrell, P.W. Moody. Commun. Soil Sci. Plant Anal., 15, 779 (1984).

[11] I. Novozamsky, D. Van Dijk, J.J. Van der Lee, V.J.G. Houba. Commun. Soil Sci. Plant Anal., 24, 1065 (1993).

[12] J. Coutinho. Commun. Soil Sci. Plant Anal., 27, 1363 (1996).

[13] L. Sun, Z. Gao, X. Yu, Z. Fang. Fenxi Huaxue, 9, 586 (1981).

[14] M.P. García, P.L.A. Puchades, A.M. Catalá. Soil Sci., 151, 349 (1991).

[15] J.L. Coventry, D.J. Halliwell, D.M. Nash. Aust. J. Soil Res., 39, 415 (2001). 
[16] Z. Chen, P. Grierson, M.A. Adams. Anal. Chim. Acta, 363, 191 (1998).

[17] V.J.G. Houba, J.J. Van der Lee, I. Novozamsky. In Soil Analysis Procedures - Other Procedures, Part 5B, pp. 143-145, Wageningen Agricultural University, (1995).

[18] International Union of Pure and Applied Chemistry (IUPAC), Anal. Chem., 48, 2294 (1976).

[19] J.C. Miller, J.N. Miller. In Statistics for Analytical Chemistry, Ch. 5, pp. 120-124, Ellis Horwood, New York (1993). 